\title{
An investigation of lentic water quality parameters and its suitability to irrigated agriculture
}

\author{
DEEPA N. BARKI AND PRADEEP KUMAR SINGA
}

\begin{abstract}
The water bodies are facing a severe threat of pollution all over the world. To ensure fresh water availability from the local water sources has become a big challenge. The impact of point and non-point pollution sources on the quality of the receiving water and suitability of water for irrigation was evaluated based on sodium adsorption ratio and the US salinity diagrams of the lakes was investigated during premonsoon and post-monsoon seasons that is from Dec 2013 to May 2014 The condition of the lakes deteriorated sharply in the pre-monsoon due to low dilution of incoming pollutants during the low water flow lead to the increase the pollution of the lakes. In the vicinity of intensively cultivated areas, the high concentrations of electrical conductivity, nitrogen and phosphorus which were detected in the lakes during pre-monsoon may be partly attributed to the leaching of the applied fertilizers because of nitrogen mobilization and soil erosion.
\end{abstract}

KEY WORDS : Lakes, Water quality, Parameters, Sewage, Haveri

How to cite this Article : Barki, Deepa N. and Singa, Pradeep Kumar (2014). An investigation of lentic water quality parameters and its suitability to irrigated agriculture. Engg. \& Tech. in India, 5 (1\&2): 73-79. 